\title{
A BUSCA DA
}

FECUNDIDADE DO
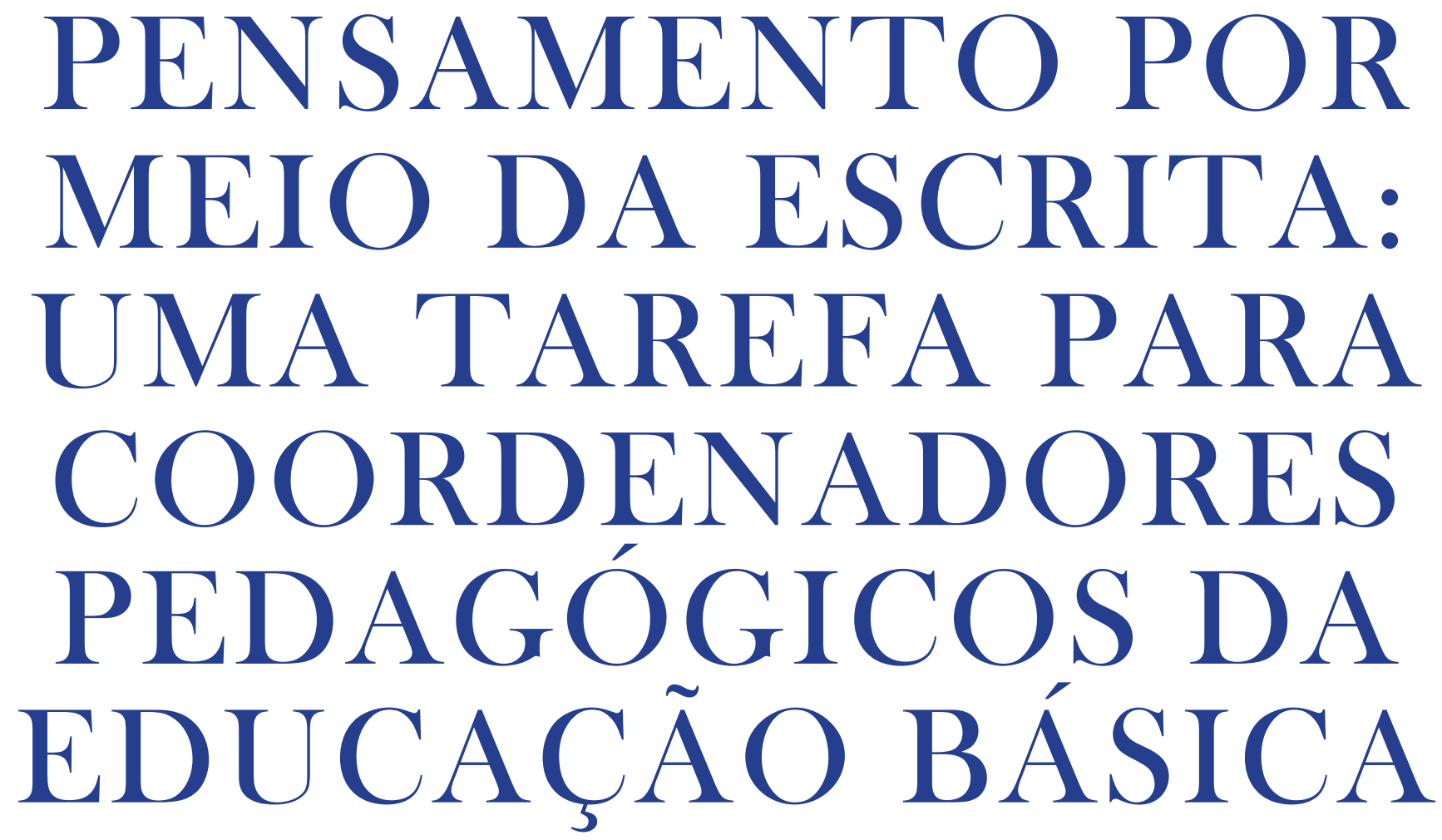

SEARCHING FOR FERTILE THINKING THROUGH THE ACT OF WRITING: A TASK FOR PEDAGOGIC COORDINATORS OF BASIC EDUCATION

LA BÚSQUEDA DE LA FECUNDIDAD DEL PENSAMIENTO POR MEDIO DE LA ESCRITURA: UNA TAREA PARA LOS COORDINADORES PEDAGÓGICOS DE LA EDUCACIÓN BÁSICA

\section{Lúcia Schneider Hardt}

Doutora em Educação pela UFRGS. Docente do Programa de PósGraduação em Educação da UFSC.

\section{Neide Martins Arrias}

Doutora em Didática pela USP.

Programa de Pós-Graduação em Educação Universidade Federal de Santa Catarina (UFSC) Florianópolis - SC - Brasil 
Endereço:

UFSC - PPGE

Trindade - Florianópolis - SC

CEP: 88040-900

E-mails:

luciashardt@gmail.com neidemartinsarrias@gmail.com

Resumo: O artigo pretende analisar uma das etapas do curso de Especialização em Coordenação Pedagógica: a produção de um artigo acadêmico, tarefa necessária para conclusão do curso. A fragilidade verificada na produção do artigo revela uma dificuldade de autoria, densidade no tratamento dos conceitos e insegurança em relação à escrita. Verifica-se um paradoxo: de um lado o profissional preparado e indicado para ensinar a ler e escrever, do outro lado uma pessoa insegura e frágil frente ao desafio da sua própria escrita.

Palavras-chave: Educação Básica. Formação. Produção Textual.

Abstract: This article analyzes the phases of a Specialization course on Pedagogic coordination: the production of an academic article, as a necessary task for the course conclusion. A weakness verified in the production of articles reveals difficulties related to authorship, density in the treatment of concepts and insecurity in respect to writing. A paradox can be seen: on one hand, we find the well-prepared Professional, enabled to teach and write; on the other hand, we see an insecure and fragile person, when faced with the challenge of writing their own text. 
Key-words: Basic education. Formation. Textual production.

Resumen: Este artículo pretende analizar una de las etapas del curso de Especialización en Coordinación Pedagógica: la producción de un artículo académico, exigencia necesaria para la conclusión del curso. La fragilidad verificada en la producción del artículo revela una dificultad de autoría, densidad en el tratamiento de los conceptos e inseguridad en relación a la redacción. Se observa una paradoja: por un lado el profesional preparado e indicado para enseñar a leer y escribir, por otro lado una persona insegura y frágil frente al reto de su propia escritura.

Palabras clave: Educación Básica. Formación. Producción Textual.

er e escrever são atividades intelectuais e em alguma medida sentirse frágil diante deste compromisso denuncia itinerários de formação específicos. Quem conhece o mundo das palavras deseja inserirse nele com alguma dignidade. Um professor enfrenta a fragilidade ao adentrar o mundo das letras em função de não estar habituado a escrever. Sua prática está centrada na fala, no diálogo, muitas vezes no excesso do fazer. A comunicação oral põe o professor mais à vontade, permite o ensaio, o retorno, o esquecimento, o reinício; já o texto escrito parece sempre deixar rastros comprometedores. Assim, professores em formação, quando solicitados a escrever, parecem travados e sentem muita dificuldade de falar de suas experiências educativas por meio do texto. Mas a escola é o lugar para ler e escrever e o educador é aquele que promove e viabiliza essas práticas. O que a experiência permitiu verificar é que em alguns momentos o professor-estudante tem dificuldade em utilizar todos os recursos da escrita quando solicitado a teorizar sobre sua ação.

Nietzsche é um filósofo que ganhou notoriedade pelos pensamentos breves, escolheu o aforismo como estilo e aprecia o pensamento oriundo do 
deslocamento. Valoriza os pensamentos "andados" e desconfia de pensamentos sedentários. Mas a brevidade da escrita não é simples, fácil. Escrever para colocar no papel o que foi concebido andando e caminhando é complexo. Exige rigor e foco. Em grande parte, os professores pensam andando, falando, deslocando-se de lugar a lugar; contudo, esta condição não gera, automaticamente, uma escrita de qualidade. Talvez, até mesmo aquilo que o professor pensa enquanto anda ainda não alcançou uma reflexão capaz de produzir um bom texto. Talvez, também, o texto não apareça, pois o professor foi formado para escrever em estilo sistemático, com muitas regras, que, em vez de ajudar, acabam por travar a escrita.

Até este ponto vale esclarecer que não está em questão fazer a defesa de textos ideais definidos por um estilo único, mas discutir os motivos que impedem a feitura de um texto mais livre e de qualidade. O curso em questão, a formação do coordenador pedagógico para as escolas públicas, é fomentado pelo Programa Escola de Gestores/Ministério da Educação/Brasil (MEC) em parceria com a Universidade Federal de Santa Catarina (UFSC/ SED/UNDIME) como expressão de uma política pública comprometida com a educação que visa qualificar a escola pública, observando em especial o Índice de Desenvolvimento da Educação (IDEB) das escolas envolvidas. O curso tem a duração de um ano e meio, sendo que nos últimos cinco meses cada aluno deve produzir um artigo como trabalho de conclusão, inspirado por um projeto intervenção (PI) praticado e vivenciado na escola.

Para produzir este artigo foi necessário retornar à plataforma, ambiente virtual de aprendizagem, já que o curso foi oferecido na modalidade a distância, para coletar material empírico que revela as inquietudes e preocupações dos alunos-professores enquanto escrevem um texto.

Para exemplificar, compartilhamos alguns de seus desabafos:

"Preciso dizer que as orientações e indicações de leituras têm contribuído para o redimensionamento da produção do artigo. Leio e releio, construo e desconstruo, mas a arte final parece ainda tão longe."

"Cada vez que releio o texto, mudo alguma coisa rsrsrsrs. Está sempre incompleto, em aberto, sem final. Foi difícil abrir o texto e agora fechá-lo."

"Considero tudo que me é enviado pelo orientador, mas nem sempre sei como ligar as partes, os textos."

Do outro lado, os orientadores afirmam:

"Senti falta da presença de vocês no fórum de nosso tema e de retornos com relação aos feedbacks dos trabalhos que os enviei. Para mim é importante saber como acolheram os comentários que fiz aos textos, compartilhar as dúvidas, solicitar outras orientações para 
que a próxima versão que me enviarem esteja o mais próximo possível do que 'será o artigo final'. Assim teremos tempo de trocar contribuições e somar solidariedades."

"Pude observar que a maioria de vocês escolheu como assunto para a reflexão, a indisciplina na escola. Isso amplia os desafios para que cada artigo seja original e não repita o 'já dito'. Esse é um conteúdo de grande complexidade, por isso, relevante, mas requer dos/as autores/as a disposição de ir além do já conhecido, a coragem de abrir as janelas mais próximas para ver o que se esconde nos detalhes não observados, 0 desejo de partir de uma 'razão sensível' para tecer explicações criativas, bem articuladas entre realidade escolar e trabalho pedagógico."

"Como coordenadores pedagógicos em suas escolas, a experiência narrada precisa contemplar os fios invisíveis que atravessam o cotidiano, os gestos sutis que dançam nas relações, os olhares que ameaçam em silêncio, os medos produzidos na hierarquia dos encontros, as dissimulações que regulam os jogos de poder, as cumplicidades entre uns e as divergências entre outros, os discursos predominantes e as práticas dissonantes, o barulho que quer anunciar algo, mas que não tem escuta... Há inúmeros fios que exigem de vocês entrelaçá-los com a experiência profissional e o assunto que escolheram para criar o artigo. Não vale ficar preso/a na mesmidade, nas frases feitas, nas linearidades dos argumentos."

"A atividade de pesquisar algo sempre apresenta um conflito que é de ordem filosófica: queremos dizer algo e, ao mesmo tempo, jamais diremos tudo em função de nossa própria condição humana. Sempre haverá algo por dizer. Então, para não corrermos o risco de nos perdermos no imenso mar de possibilidades que a pesquisa pode oferecer é importante, desde o início, termos em mente esta condição referida, bem como outra, não menos importante, que é aquela que se refere ao interesse do leitor. Precisamos manter o leitor de nosso texto atento e interessado naquilo que queremos dizer. Nesse sentido, apresentar o tema, o assunto, de maneira clara e objetiva é um cuidado importante para a captura do interesse do leitor e para o êxito do desenvolvimento do argumento também."

Observem que os orientadores, mesmo a distância, tentam se fazer próximos, reconhecendo limitações em seus orientados, contudo sem desistir de dar apoio para além do teórico, dando incentivos e motivando para que continuem.

Novamente, um estudante desabafando:

"Estou por aqui, ainda estou meio perdida sem saber por onde começar, e se possível gostaria de receber alguma orientação."

"Desculpe não ter respondido antes, mas, pra te falar a verdade, eu estava bem confusa."

\section{Volta à cena o orientador:}

"Nada de desistir... você tem muito potencial e já caminhou muito neste curso para desistir.... agora falta tão pouco. Sei que você é capaz de escrever um belo artigo."

Os diálogos entre alunos/professores e orientadores têm este tom, repetemse em uma variedade significativa de possibilidades, apresentando-se em torno desta lógica: o estudante aflito e inseguro para escrever e um orientador 
disposto a colaborar e fazê-lo escrever. Depois ainda virá outro drama, apresentar e defender seu artigo publicamente.

Os alunos-professores insistem com afirmações do tipo: confusão de ideias, dispersão, pouco a dizer, as partes não se ligam, não saber por onde começar, escrever para além do óbvio, tema demasiadamente aberto, sem foco.

As estratégias do curso e dos orientadores era fazer pensar para inclusive analisar se aquilo já era presença no texto para então identificar a falta, o complemento ainda ausente, o bom argumento e a falta dele, os cruzamentos e as trocas, definir um método adequado para dar visibilidade ao tema. As vivências na escola foram efetivadas, cabia então analisar o que aconteceu identificando sentidos pedagógicos. Evitar um texto simplório, descritivo apenas, mas tomar autores estudados no curso para que eles possam ajudar a entender as práticas e avançar na reflexão.

O curso forma adultos, e adultos não deveriam resistir a uma interação mais objetiva, direta, criteriosa no sentido de reconhecer o valor da exigência de qualidade. Da mesma forma, como alunos adultos precisam ter um espaço para indicar eventuais fragilidades que devem ser corrigidas no decorrer do processo.

Cuidado não pode ser tutela. Temos de criar espaço para que esse adulto não se infantilize; contudo, também não podemos dispensar o cuidado. Nesse caso, o cuidado implica estar no ambiente, dar respostas, participar dos fóruns, acionar as burocracias administrativas quando necessário. O desejo e o dever de ler os textos é condição de um adulto minimamente bem crescido. Da inviabilidade disso, os motivos devem ser analisados criteriosamente. Motivos justos e já reconhecidos em parte estiveram apontados durante todo curso: falta de tempo, dificuldade dos textos e, portanto, necessidade de mediação de outros adultos, excesso de trabalho. Dispensar a tutela não é dispensar a didática. Adulto em formação exige uma didática específica. Assim, o curso exigiu a presença constante do professor-coordenador de sala ambiente inicialmente, e depois o professor-orientador para produzir o texto. De toda forma, o empenho de toda equipe envolvida foi garantir uma formação de qualidade, reconhecendo que alguns desafios ainda ficam indicados, merecendo nossa atenção e reflexão.

O curso deseja especializar coordenadores pedagógicos, responsáveis pelas dinâmicas mais importantes da escola. Sabemos que a vida de um coordenador não é simples, está tocada pela interrupção, incoerência e pela surpresa. Quando imagina ter encaminhado um problema, ele aparece de outra forma, surpreendese e, por vezes, tomba diante da realidade. Essa instantaneidade frustra, ainda que reconheçamos que de alguma forma também não toleramos mais o que 
dura para sempre. Segundo Bauman (1999), vivemos essa ambiguidade entre a solidez e a liquidez. Os sólidos implicam resistência à mudança, o que ligou as formas sólidas está garantido. Já os líquidos não mantêm sua forma com facilidade, eles escorregam, respingam, vazam, inundam, borrifam. Os contornos não seguram os líquidos. Mas seria o mundo sólido melhor? Se prestarmos bem atenção, os movimentos de resistência e liberdade implicaram sempre fazer derreter mundos sólidos, livrar-se de entulhos das velhas ordens. O que seria recomendável que durasse? Como lidar com as práticas educativas, considerando a velocidade e a aceleração com que os princípios ficam estabelecidos e, por vezes, interessadamente definidos?

Hoje, as principais técnicas de resistência parecem ser a fuga, a astúcia, o desvio, a evitação. Os sujeitos se defendem por essas trilhas e quem está na condição da mediação tem dificuldades em estabelecer um itinerário de trabalho e enfrentamento de crises. Nossa luta parece ser uma luta, como diz Bauman (1999), contra a arte da fuga. Para que tudo possa fluir, o mundo deve estar livre de cercas, barreiras, fronteiras e barricadas. Mas o mundo pedagógico necessita de indicadores, não podemos derrubar todas as cercas. Afinal, o que deve ser preservado e o que o deve ser tocado para mudar?

Qual a função do curso diante desse cenário? Formar neste contexto significa agir e pensar e nesse aspecto escrever é um exercício necessário sobre as ações que foram concretizadas na escola.

Concretizar esse processo não é ocupar-se com algo simplesmente, moralizar o campo de ação, mas fazer emergir sentidos para o "estar aí" sem obrigarse a resultados simplesmente. Não podemos esgotar as energias no mundo das vivências, mas cavar espaços para refletir sobre o mundo da existência humana. A familiaridade no contexto pedagógico implica o fazer pedagógico que sempre é menor que o agir pedagógico. Enquanto nos compreendemos, temos mais uma vez a chance de repor a pergunta pelo sentido do ser. Ser professor, ser coordenador pedagógico.

A angústia produz em nós disposição de abertura e cria possibilidades para o cuidado, considera a condição de incompletude do ser humano, desafia a cada profissional fazer algo e que possa ser significativo.

Estar excessivamente envolvido pelas ocupações do presente nos conduz a um estado de decadência. Enxergar apenas o imediato impede a possibilidade de planejar o futuro. $O$ existir autêntico é um desafio bem maior que imaginamos e nessa direção muitas seduções nos desviam da possibilidade de colocar-se no mundo eticamente. Para Heidegger, citado por Dalbosco (2006), cuidado significa estar à frente de si mesmo, envolvido com entes no mundo e isso 
implica responsabilidade. Ao tocar interessadamente nessa teoria em função do curso de formação, parece que não há como escapar dessa interface. A dimensão que o curso se coloca evidencia essa vontade de estar à frente de si mesmo para entender esse nosso tempo, investigar nossa decadência e lançarse ao futuro com outras possibilidades. Por isso podemos enfrentar nossa angústia sem adoecer, evadir-se ou desistir de um curso.

Uma primeira recomendação: evitar ocupar todo o espaço nesse esforço, permitir o fenômeno da abertura. Isso implica, por vezes, rever o que já está definido, não deixar-se seduzir por suas próprias ocupações e convicções. As ocupações podem nos cegar e impedir o fenômeno da abertura.

O cuidado implica uma espécie de cura que ocorre considerando nossa temporalidade e impulsiona nosso agir, nossa vontade de estar no mundo plenamente. E quando não conseguimos isso, a angústia se materializa. A angústia rompe com o conforto da familiaridade, do já conhecido e nos coloca na presença da estranheza do mundo no qual precisamos de novo pensar nossas ocupações. Formar-se implica ser tocado por isso que de certa forma é de novo um rastro do fenômeno da abertura.

Pensemos a função do coordenador considerando essas indagações. Qual o tempo que existe para este exercício? O tempo é escasso e é preciso aprender algumas estratégias para otimizar este tempo e aprender a refletir sobre os cotidianos educativos.

No livro a Bússola do escrever (2006), Garcia e Alves recomendam alguns cuidados no processo da escrita:

1. O que é para nós ver, como aprendemos a ver a realidade. Em tempos modernos ver parece ser o sujeito coberto de lentes de todo tipo, eficientes e sofisticadas, que tudo vê e percebe. O mergulho no tema deve ser mais amplo, não basta apenas ver uma perspectiva, devemos alargar o cenário do tema para inserir outros personagens que também estão vendo e pensando a respeito;

2. Compreender que o conjunto de teorias, categorias, conceitos e noções que herdamos nem sempre resolvem o enigma da pesquisa, por vezes são até limites ao que precisa ser criado/tecido. Isto não nos autoriza a dispensar as categorias, mas a colocá-las no jogo da investigação, por vezes até virálas de cabeça para baixo;

3. Reconhecer que as fontes para a pesquisa devem ser arejadas, é preciso lidar com a noção de complexidade que exige uma curiosidade para verificar como um tema pode ser abordado por perspectivas diferentes, desde as 
fontes orais, documentais e bibliográficas;

4. Além desses três itens, as autoras anunciam que hoje, para comunicar algo novo, é preciso escrever de outro jeito. A escrita está carente de novidade e criatividade. Muito engessada e convertida em manual e dissertações burocráticas.

Cada um desses itens ajuda no sentido de compreender a fragilidade da escrita dos alunos/professores. Quem pesquisa deve sentir o fragmento de mundo em questão, não basta contemplar, assistir; em geral, as misérias daqueles que assistimos para pesquisar estão muito próximas das nossas. Ver toda a realidade com objetividade é impossível. Não existe esta tão desejada objetividade, nesses termos o texto já pode anunciar este caminho tortuoso, mas também criativo. Evitar os excessos de descrições, tão assépticas quanto inodoras e distantes de um pulsar humano. Que sejamos capazes conforme dizem as autoras:

De mergulhar inteiramente em uma determinada realidade, captando sutilezas sonoras, sentindo a variedade de sabores, tocando coisas e pessoas e nos deixando tocar por elas, cheirando os cheiros que estão em cada ponto de nosso caminho diário e aprendendo a ler o corpo, este desconhecido que tantos sinais incompreensíveis nos dá. (GARCIA; ALVES, 2006, p. 261).

Estamos nos referindo aqui especialmente a pesquisas que têm um alto compromisso com o cotidiano no nosso campo epistemológico: a educação. Por isto, é necessário ter um sentimento de mundo, sem ser falacioso, nem banal e ingênuo. Não conseguimos entender as muitas lógicas da escola se imaginamos poder ser absolutamente neutros, é preciso um mergulho na realidade. Neste ponto todos os alunos/professores tinham uma aproximação com a realidade, mas talvez ainda não olhando de dentro, e perdendo por vezes temperos da vida cotidiana que não escapam a um pesquisador atento: verificar tudo o que se passa, no que se acredita, o que se repete, aquilo que quer mudar e o que não se deixa mudar. Capturar o detalhe para compreender as dinâmicas da vida em uma escola. Estamos ainda viciados por treinamentos que ensinaram a olhar de forma neutra, mas precisamos tomar outras ferramentas, prestar a atenção nos conteúdos oferecidos pelo curso para observar com mais leveza, definir estratégias de pesquisa adequadas à nossa curiosidade.

Um dos temas muito investigados nos artigos foi a necessidade de uma gestão democrática, identificando dificuldades neste processo. Observar, tomar dados para pensar este tema significa mergulhar na realidade da escola. Não bastava apenas descrever o falado, mas capturar detalhes do cotidiano, não como um juiz pronto a julgar, mas como observador atento que deseja encontrar onde se encontram os reais impedimentos desta prática. 
Não devemos encaixar a fala dos outros e as suas práticas em nossas noções prévias, por isto precisamos de mediadores que, em geral, podem ser as categorias teóricas que não apenas definem as coisas para nós, mas insinuam possíveis interpretações e nos deixam a tarefa para concluir.

Sobre o segundo ponto indicado pelas autoras: estamos encharcados de profecias sobre a coerência, a verdade, a solidez teórica. Sem dúvida precisamos de teoria, por vezes mais de uma, aquelas que ficam à disposição em função do tema para assim romper as fronteiras da coerência sem tornarse irracional, mas fazendo com que as teorias conversem entre si em função do problema que desejamos investigar. Até mesmo uma teoria pode ser contestada; contudo, é preciso muito estudar, conhecer os argumentos de cada uma para ver a pertinência de nossas perguntas e os dados que chegamos a reunir. Neste ponto uma grande fragilidade: o entendimento mais comum é imaginar um ajuste entre o empírico e o teórico, como se fosse possível uma justaposição. O texto fica linear, programado, jogralizado, perdendo a beleza da curiosidade e da formulação de hipóteses. O caminho seria criar uma nova organização do pensamento, fazendo as categorias dançar a favor do tema, para responder perguntas que ainda não foram feitas. Imaginemos a questão da violência, tão definida já, todas as causas listadas, procedimentos afirmados e de tanta clareza não conseguimos compreender um elemento novo que a pesquisa pode trazer, por exemplo: a afirmação da violência pedagógica da avaliação. Neste momento, o tema pode virar de lado, já não está mais na criança, no jovem, na família, mas está na escola, no professor. Esta realidade nos obrigaria a rever o que aparentemente está definido, escrever outro texto, selecionar outros conceitos, provocar o problema em seu próprio território.

O terceiro ponto fala das fontes, dos muitos tipos de fonte, também aquelas faladas, contadas na escola. Os documentos de escola, os registros, as atas, os boletins. Tomar o frequente da escola e verificar a variedade de uso ou não deste recurso. A existência de sempre mais variedade em termos de fontes nos obriga a criar formas novas para captar e registrar no texto o que pode entrar em cena com outra roupagem.

E voltamos ao quarto ponto, que é o encontro com a própria linguagem, o maior limite. Em geral, a aprendizagem da escrita deu-se por meio de exercícios, questionários, exigindo respostas previsíveis, caminhos retos, desprezadores dos ensaios e dos erros. Poucos encontros com a literatura e a poesia. Textos lineares, duros, herméticos, fruto de exercícios e treinamentos não dão conta de falar da beleza do cotidiano. Aqui vale ressaltar a leitura como recurso para escrever bem. A leitura revela os muitos modos de ver e nesse contato surge 
o desejo de também registrar o próprio modo de ver. As metáforas surgiram para abrir outros canais para o entendimento, podemos aprender como utilizálas e até mesmo como criá-las. Quanta leitura nos falta? E nos falta não para prestar conta, mas para dar solidez ao cenário de fundo onde nosso tema deseja apresentar-se. Sem cenário, ficamos seduzidos a interpretar o objeto por meio de opiniões, recolhidas, muitas vezes, das primeiras impressões.

Até aqui a tentativa de compreender a fragilidade, jamais negá-la, já que está entre nós. Enfrentar um texto ainda sem beleza ou incrementar mais um texto vai exigir a presença do orientador. Aquele já referido anteriormente e que tem uma função importantíssima.

A função de orientador impõe a presença de muitos textos, várias entregas, várias versões. E mais, exige compulsivamente um dizer diante dos textos. Uma prática por vezes curiosa, por vezes estafante, quando o que se tem a dizer precisa mais de rigor e correção que palavras de conforto ou incentivo. A condição para o dizer é uma condição polifônica, o texto abriga muitas vozes, mas cabe a cada texto dar à quantidade de vozes algum tipo de singularidade. Desse ponto devemos ter mais intuição que normas e regras. Uma intuição temperada pela consistência, pela seleção artesanal das palavras, o corte cirúrgico de outras para dar ao texto uma voz que garanta pelo menos uma sonoridade aos espíritos curiosos. Esta intervenção passa pelas mãos do orientador.

Afinal, como nos tornamos o que somos? Será preciso ver a si mesmo, reconhecer as escolhas feitas, aquelas impostas, aquelas que nem percebemos que poderíamos ter feito quando escrevemos um texto. Em grande medida nem sabemos quem somos e por isso esbanjamos energia em lugares inadequados. Naufragamos quando nos esquecemos, estreitamo-nos, apequenamo-nos. $O$ ato que nesse ponto surge é aquele que foi impedido de ser cultivado, esqueceu que existia, não buscou a nutrição adequada, mergulhou em clima e lugar inadequados e deixou-se configurar, quando não morrer. Mesmo na academia corremos o risco de morrer por conta das rotinas já incorporadas. O orientador de um texto deve saber cultivar no estudante os seus próprios temperos para ajudá-lo na dosagem de cada coisa e também na dispensa do que não cabe e é inadequado para o texto. Uma espécie de gastronomia das palavras que, em vez de chegar à boa mesa, deseja alcançar uma boa defesa.

É preciso uma cultura de fundo para bem escrever. Neste ponto, outra lição: nosso destino não é ser um espírito cativo que apenas repete uma tradição, podemos ser livres, capazes de tomar a tradição para pensar outra vez. A tradição deve nos seduzir a pensar, a nos colocar diante de outros desafios, considerando o que a humanidade já pensou, assim aquilo que podemos 
acumular não nos torna cativos, mas nos liberta a continuar a realizar a tarefa de responder ao mundo com nosso tempero e estilo.

Montaigne, o artesão da dúvida, consolidou outra forma de escrever: os ensaios. Diz ele enquanto escreve: "é loucura condicionar ao nosso discernimento o verdadeiro e o falso" (2002, p. 267), abordagem interessante para continuar a dialogar sobre textos quando o que fica recomendado é a prudência intelectual. As medidas da nossa suposta inteligência não são compatíveis com a complexidade do real. A familiaridade ou a estranheza das coisas ocorrem mais em função de nossos hábitos que em função de nossa capacidade de conhecer. Nessa direção, a prudência e a curiosidade devem ser mantidas. Presunção, segundo Montaigne (2002), não é um bom tempero para escrever. Corremos o risco de falar mais de nós mesmos que de um tema, de um problema, de uma curiosidade.

Assim, o que estava posto como cultura de fundo é de tal forma aqui considerada que o fundo tem também um espaço para o enigma, existe um espaço para o inusitado, está implícita uma ideia de que nem tudo esteja decifrado. Esse fundo apresenta ainda pontos para serem pensados, tocados e não levianamente definidos. E mais, diz Montaigne: "é uma ousadia perigosa e considerável, além da absurda temeridade que traz consigo desprezar o que não compreendemos".

O texto que está por ser escrito não poderá jamais tudo contemplar, nem tudo descrever, mas nem por isso podemos desprezar o que não foi possível, não conseguimos escrever considerando nosso horizonte de pesquisa e de cultura. Nessa direção, Montaigne sugere os ensaios como outro gênero da escrita, que possa tomar a vida para abrigá-la em outros estilos estéticos que não a compulsão descritiva para mostrar a verdade. Reduzir a vida e os seus dilemas a um formato científico, garantindo o pleno discernimento das variáveis em questão, tira da cultura de fundo as grandes motivações da humanidade que sempre partiram de perguntas e não de respostas.

E Montaigne segue provocando sobre o tema, dizendo que o melhor seria ter certeza de que a mentira pudesse ser controlada pelo seu oposto, dando lugar à verdade. Mas esse oposto apresenta mil faces, restando ficar alerta tanto em relação à verdade quanto em relação à mentira.

Parece interessante pensar nesta direção: um texto fechado de verdades em geral torna-se dogmático, e um texto cheio de fragilidades e tagarelices dispensa leitura. Não precisaria, portanto, ser escrito. Por sua vez, um texto mergulhado no desejo não responde à curiosidade da alma, rasga o coração de perguntas sem ser capaz de produzir qualquer aconchego. Assim o ensaio de algumas respostas é eticamente recomendável e possivelmente saudável. 
Nietzsche ataca a escrita feita de promessas e escreve com agudeza e crueza sobre temas humanos, demasiado humanos. Compreende-se como póstumo, uma vez que nem seus mais próximos compreendem o que fica para ser pensado, mas parece convencido que o querer do sangue tornou-se palavra. É preciso escrever com sangue.

Como Montaigne, Nietzsche revela as mil faces da verdade e defende o perspectivismo. Ele surge na relação com a vida, nascida do caos e estruturada por múltiplas versões capazes de nos fazer viver apesar do caos. Interpretamos para criar um texto, essa é a lição de Nietzsche. Tal atitude implica conseguir viver diante do caos e das mil e uma faces da vida. Queremos enfrentar o caos e criamos uma medida de ordem, capaz de ter beleza, o sentido e, deste modo, o bem-estar.

O texto que se deseja na academia também poderia ter mil faces, mas precisamos dar uma ordem para poder escapar do caos e dar com sangue uma materialidade ao nosso espírito criador. Afinal, nosso texto deseja leitores e nesta direção é preciso escapar do caos. Em geral, nossos textos têm muito de desordem, de face única, de sedução, de fraco discernimento, de matérias excessivas do armazém da memória que nada selecionou, apenas acumulou. Orientar parece ser lidar com tudo isso e, ainda assim, preservar-se, pois tanto aluno como professor serão formados enquanto tomam os textos para criar estruturas criativas. A interação entre estudante e orientador mostra uma possibilidade e um limite: Afinal, qual o texto que podemos fazer nascer? Que presença é necessária para que um texto alcance a beleza?

Escrever um texto provoca cansaço, esgotamento, pode até fazer adoecer e, em alguns casos, isso de fato aconteceu com muitos de nossos alunosprofessores. É possível enfrentar este limite por meio de uma convivência honesta capaz de produzir deslocamentos no aluno escritor que reconhece suas fragilidades e aceita ser conduzido, cuidado, sem ser tutelado. Implica suportar ser corrigido, avaliado, solicitado. Afinal, avaliação é também uma forma de presença que deseja o desenvolvimento do estudante.

Sem esquecer que o empenho exige uma arte - a arte de bem escrever - tarefa humana de muito tempo, ensinada e aprendida de muitas formas, banalizada tantas vezes, e que sempre deve ser buscada novamente nos processos de formação. Alguns ainda ficarão nos rascunhos da arte, ensaiando traços e formatos, outros já alcançam por meio do seu texto um estilo artístico-estético. Parece mesmo que o exercício da escrita em um curso de especialização captura pelo menos dois sujeitos que, pautados pelo desejo e o dever, precisam se ver com sua formação para sempre que possível e necessário alargar e qualificar o que se diz sobre a alma humana, especialmente no campo da Educação. 


\section{REFERÊNCIAS}

ALVES, N.; GARCIA, R. L. A necessidade de orientação coletiva nos estudos sobre cotidiano-duas experiências. In: BIANCHETTI, Machado (org.). Bússola do escrever. 2. ed. Florianópolis: Ed. UFSC; São Paulo: Cortez, 2006.

BAUMAN, Zygmunt. Modernidade e ambivalência. Rio de Janeiro: Jorge Zahar, 1999.

DALBOSCO, Claudio Almir. O cuidado como conceito articulador de uma nova relação entre filosofia e pedagogia. Educação e Sociedade, v. 27, n. 97, p. 11131135, 2006.

MONTAIGNE, Michael. Os ensaios. Livro I. São Paulo: Martins Fontes, 2002.

NIETZSCHE, Friedrich. Assim falava Zaratustra: um livro para todos e para ninguém. Petrópolis, RJ: Vozes, 2007.

. O crepúsculo dos ídolos ou, como se filosofa com o martelo. São Paulo: Companhia das Letras, 2006.

. Ecce homo. Porto Alegre: L\&PM, 2003.

Artigo recebido em 04/08/2013

Aprovado em 18/02/2014 